repeated, pains and violent cramps. On the contrary, paralysis is a very common consequence of the colic, when it has attacked the patient for the second or third time. The paralysis is very refractory under treatment.

Chronic affections of the abdominal viscera sometimes follow the disease; but more usually health is restored after a few days' debility and dyspepsia.

Dr. Hisern has observed, that men are more frequently attacked than women.

\section{Cause of the Disease.}

The practitioners of Madrid are divided in opinion as to the cause of this malady; some attribute it to the poison of lead; others to the influence of climate, or the vicissitudes of seasons; others, in fine, think that the common articles of diet disagree with the individual, and give rise to colic.

M. Hisern agrees with those who attribute the disease to the influence of lead, and considers that this poiscn is introduced into the system in three ways :-

1st. The water used for drinking in Madrid contains hardly any salts, but has a sharp, agreeable flavour, which induces $M$. Hisern to infer, that it contains carbonic acid gas, and that a carbonate of lead is formed by the action of this gas on the leaden pipes that convey the water. It is to be regretted that $M$. Hisern has not performed experiments to decide this point, but it is highly probable his conjectures are well-founded; and if this be the case, we can account, to a certain extent, for the greater frequency of the colic in men, who, exerting their muscles to a greater degree for the purposes of labour or amusement, and of course requiring more drink on this account, and owing to their freer indulgence in wine, than women, must swallow a larger quantity of lead.

2d. The wines used by wealthy persons are alcoholic, and free from acidity; but people of the middle and lower classes drink the wine of the neighbourhood, which is very weak and acid. This acidity is the cause of frequent adulteration with lead. Here, again, we are furnished with a fact explaining the greater frequency of Madrid colic in men, who use wine more freely than the other sex.

$3 d$. The people of Madrid, but especially the common people, eat large quantities of pickles. Persons in easy circumstances keep their pickles in glass vessels, but the working people preserve them in earthern vessels glased with lead. Dr. Hisern relates a case of violent colic supervening suddenly after a meal, and produced by the vinegar in a pickle jar corroding the glazing, and forming the aretate of lead, the existence of which salt in solution was ascertained by him.

But as so few of the inhabitants are attacked, and as strangers are more subject to the aisease than old inhabitants, M. Hisern thinks that something more is necessary to account for the disease, and believes that there must be some predisposition, or that causes as yet not well understood must operate to make certain persons more liable to the disease than others.

The colic is more prevalent in summer and autumn than at other times; but this is not attributed by M. Hisern to any influence of season, but to the fact, that the leaden tubes are then half empty, and admit air, which facilitates the formation of the carbonate of lead.

There is nothing worthy of notice in the treatment of $M$. Hisern ; he prescribes narcotics, baths, mild purgatives, frequently repeated, in preference to the more active remedies of this class, and occasionally alum.-Revue Medicale.

\section{PHYSIOLOGY OF THE NERVOUS SYSTEM.}

M. Nonat has presented to the Royal Academy of Medicine of Paris a memoir having the following title : " Experimental Researches into the Functions of the Encephalon, viewed in reference to their relations with Sensation and Muscular Contraction." M. Nonat has arrived at the following conclusions:-

1st. The three great nervous centres, the spinal marrow and nerves, the brain and cerebellum, have distinct and special functions.

2d. The spinal marrow and nerves preside over sensation and muscular action.

3d. The functions of the brain consist in the exercise of the will and the consciousness of sensations.

4th. The cerebellum exercises an influence (as yet imperfectly ascertained) over locomotion, and the control of muscular action ("station").

At a subsequent meeting of the Academy an animated discussion of $M$. Nonat's views took place, when Messrs. Rouvier, Londe, Bouillaud, Gerdy, Castel, and Rochoux, successively spoke. The Academy, adopting the recommendations of $M$. Bouillaud, the author of the report, determined that M. Nonat should be thanked for his essay; that he should be requested to continue his inquiries, and to send his memoir to the committee of publication; and that his name should be enrolled as a candidate.-Revue Méd.

[It will be observed that $M$. Nonat means by the term "sensation," the effect produced upon the spinal cord by impressions conveyed from the peripheral extremities of the nerves; and that by "consciousness of sensation," he intends to express that the impressions thus carried to the cord, have been transmitted to the brain proper, and converted into perceptions.

In his third inference, all mention is omitted of the intellectual operations, which, in addition to conscioushess and the exercise of the will, have their seat in the brain; this omission is owing, we suppose, to some error of the French journal's reporter.-EDs.]

\section{SQUINT QUACKERY.}

TO THE EDITORS OF THE PROVINCIAL MEDICAL AND SURGICAL JOURNAL.

Gentremen,-I beg to forward to you the enclosed advertisement, which speaks for itself. Much has been said of late about quackery, and the necessity of putting down quack medicines, \&c. but I humbly conceive, that nothing effectual in this way can be done as long as the regular members of the profession lend themselves to practices which were supposed, hitherto, to belong exclusively to gentlemen of the Morison and Eady class.-Your obedient J. $\mathrm{H}$.

Preston, Nov. 28. 1840.

"Cure of Squintive.-Mr. Harris, Surgeon, of Preston, has the honour to inform the inhabitants of Blackburn and the neighbourhood, that having successfully performed the new operation in cases of squinting, for the removal of that defect, he will attend for the same purpose at the Hotel, in Blackburn, on Thursday, the 12th instant, and the following 'Thursdays."

VArying Effects of Remedies.-The following anecdote, mentioned the other day by Dr. Bright, in one of his clinical lectures, is no less interesting than instructive. The doctor was speaking of the varying effects of the pulverised ipecacuanha in different individuals-the high susceptibility of some to its influence-and in illustration remarked, "I have now under my care an old lady who is severely affected by half a grain; and I have heard that one of the physicians to George IV., Sir Gilbert Blane, I believe, once fell into a little disgrace from an error in the use of this drug. Being called on to prescribe for some slight ailment, he incautiously, and without much thought, ordered Dover's powder. At his visit the following morning the king met him with a reproachful look, and said, - Well, Sir Gilbert, you have made me excessively sick; you know I cannot bear ipecacuan.' 'I beg your majesty's pardon,' replied the knight; 'I have given you nothing more than Dorer's powder.' 'Indeed,' said the king, 'and does not that contain some?' " 